\title{
Evaluation of a nursing handoff educational bundle to improve nursing student handoff communications: A pilot study
}

\author{
Margaret A. Avallone ${ }^{* 1,2}$, Yvonne L. Weideman ${ }^{2}$ \\ ${ }^{1}$ School of Nursing-Camden, Rutgers University, Camden, New Jersey, United States \\ ${ }^{2}$ School of Nursing, Duquesne University, Pittsburgh, Pennsylvania, United States
}

Received: April 12, 2015

Accepted: May 3, 2015

Online Published: May 26, 2015

DOI: $10.5430 /$ jnep.v5n8p65

URL: http://dx.doi.org/10.5430/jnep.v5n8p65

\begin{abstract}
Background: Inadequate handoff education in prelicensure nursing programs may pose a significant latent safety risk. This pilot study evaluates a Nursing Handoff Educational Bundle (NHEB) for a cohort of Accelerated Bachelor of Science (ABS) nursing students. The Evidence-Based Bundle consists of an educational workshop, a standardized handoff format, clinical faculty education, and structured, formative evaluation of student handoffs. This study was implemented during Adult Health clinical experiences conducted at four different University-affiliated healthcare institutions in the Northeastern United States. Methods: A pre-test, post-test design was used with a convenience sample of 28 ABS nursing students. Fourteen students who received the NHEB were compared to a similar group $(n=14)$ who were not exposed. Student handoffs were observed and rated using the Handoff Clinical Examination (CEX) tool while providing and receiving handoffs during clinical experiences. Data was obtained at the beginning and the end of a 15 -week time period.

Results: The provider handoff scores in the intervention group improved significantly $(\mathrm{M}=4.64, \mathrm{SD}=1.3)$ over the comparison group change scores ( $\mathrm{M}=1.5$, SD 1.34) when measured by independent samples $t$-test $(t=7.33, p=.000)$. The handoff recipients' scores in the intervention group also improved significantly $(\mathrm{m}=5.5, \mathrm{SD}=1.01)$ compared to no improvement in the recipient control group $(\mathrm{M}=-0.36, \mathrm{SD}=1.39),(t=12.7, p=.000)$.

Conclusions: Without structured handoff education, nursing students are passive recipients during handoffs and do not engage in safety communication practices. Exposure to a NHEB improves student handoff communication skills and provides an opportunity to practice evidence-based handoff skills with structured support during clinical experiences. The NHEB could be considered for incorporation into prelicensure programs. Further study using a larger sample size is recommended based on these preliminary findings. Additionally, this intervention should be evaluated in novice nurse cohorts.
\end{abstract}

Key Words: Handoff, Handover, Nursing education, Shared mental model

\section{INTRODUCTION}

A nursing handoff, or handover, is a complex communication process that transfers essential information, responsibility, and accountability for the care of a patient from one nursing professional to another. ${ }^{[1]}$ Many researchers have found handoffs to be inaccurate, inconsistent with patient findings, unstructured, inefficient, and often missing crucial information. ${ }^{[2-4]}$ Furthermore, ineffective handoffs have been associated with near misses, adverse events, failure to rescue, and sentinel events. ${ }^{[5,6]}$ The handoff is cognitively taxing,

*Correspondence: Margaret A. Avallone; Email: margaret.avallone@ rutgers.edu; Address: School of Nursing, Rutgers University, 215 North 3rd St. Camden, New Jersey, United States. 
especially for novices ${ }^{[7]}$ as demonstrated by the fact that handoff failures have been implicated in seven out of eight novice nurses' near miss and adverse events. ${ }^{[8]}$ A near-miss is an event that could have, but did not ultimately result in an accident or injury. The near-miss may have been averted by chance or by a timely intervention by a member of the healthcare team. ${ }^{[8]}$

Handoff education has been identified as a Quality and Safety Education in Nursing (QSEN) prelicensure competency. ${ }^{[9]}$ Though there is recognition that handoff communication skills are essential components of undergraduate nursing education, ${ }^{[10,11]}$ there is little research regarding the best methods for providing this education to nursing students. The process to learn handoff communication in prelicensure nursing programs is often unpredictable and dependent on clinical experiences. ${ }^{[7]}$ Students are exposed to multiple clinical sites and witness variability in handoff practices among different institutions. Following graduation, new nurses rarely receive formalized handoff education. ${ }^{[3]}$ Instead, professionals often learn this important safety skill by "modeling equally unskilled peers". ${ }^{[12]}$ This inconsistency in handoff preparation for student nurses and new nurses creates a latent safety risk. Safety education, including handoff education, may help build more highly reliable healthcare organizations by promoting safer communication skills. ${ }^{[10]}$ This paper describes a pilot study evaluating a bundled, standardized educational intervention to improve handoff communications in a cohort of Accelerated Bachelor of Science (ABS) nursing students.

\subsection{Creating a shared mental model}

Mental models are cognitive structures that help individuals describe, understand, and make predictions about their world. ${ }^{[13]}$ A shared mental model is necessary during patient handoffs so that the on-coming caregiver can construct an accurate overall picture of priorities and pending events. ${ }^{[14]}$ Handoff participants must use effective communication techniques to develop a common, or shared, mental model between participants. Two-way, face-to-face communication, and interactive questioning between both handoff provider and receiver have been identified as best practices to help handoff participants develop an accurate, shared mental model..$^{[7,15]}$ During the handoff communication, it is crucial for the receiver to be an active participant in order to create a shared common understanding of the patient and pending priorities. ${ }^{[15]}$

\subsection{Differences between novice and expert handoffs}

Considering the importance of interactive questioning between handoff providers and receivers in the development of a shared mental model, studies have demonstrated important safety differences between novice and experienced nurses' handoffs. Taylor observed that experienced nurses (experts) asked more clarifying questions and demonstrated more effective communication techniques during handoffs compared to novices who were primarily silent during handoffs. ${ }^{[16]}$ In a systematic review, Holly \& Poletick also noted that new nurses rarely asked questions during handoffs. ${ }^{[2]}$ Horwitz et al. ${ }^{[17]}$ scored experienced nurses significantly higher in handoff performance when providing or receiving handoff compared to nurses with less than five years of experience. In a study of physician, nurse, and nurse practitioner handoffs, experts in all groups were found to ask more effective questions to detect errors, clarify information, and correct assumptions. ${ }^{[15]}$ The differences between expert and novice nurses may be due to novice nurses not possessing the clinical salience and judgment to recognize and communicate safety concerns in a handoff report. It may also be due to the lack of recognition of the important role of the receiver in the handoff. It is critical that the student and novice nurse providing or receiving handoffs receive education, structure, supervision, and support to learn effective communication skills for safe patient handoffs.

\subsection{Handoff education}

The nursing literature is awash in publications about handoff practice, but there is comparably limited literature describing the effects of handoff education on nursing student handoff communication skills. Kesten describes the use of role-play to improve nursing student skills using a standardized handoff template. ${ }^{[18]}$ Gore et al. describes the use of student handoff communication tools and a process to develop student handoff skills. ${ }^{[19]}$ There is also literature describing the effective use of simulation to provide safety communication education in undergraduate nursing education. ${ }^{[20-22]}$ Safety simulation should mimic the complexities in real life by simulating missing information and complex situations. ${ }^{[23]}$

While there is limited literature on nursing prelicensure handoff education, other disciplines such as medicine provide guidance on curricular approaches to handoff education. With the advent of medical resident duty hour restrictions in the United States, the Accreditation Council for Graduate Medical Education (ACGME) requires that Schools of Medicine and Medical Residency programs ensure and monitor the effectiveness of resident handoffs. ${ }^{[24]}$ To that end, there are a large number of published reports describing physician resident handoff educational initiatives and outcomes. $^{[25-31]}$ The European Handover Group ${ }^{[32]}$ recommends that handoff learning for all healthcare professionals be formalized and incorporated into clinical practice with formal learning goals, measurements, supervision, and guided 
practice. Clinical faculty must have the knowledge and skills to teach, mentor, and evaluate student handoffs; therefore faculty development must be a necessary part of any successful handoff educational strategy. ${ }^{[33]}$

Starmer and colleagues demonstrated that implementation of a Handoff Educational Bundle for medical residents significantly reduced medical errors and rate of preventable adverse events. ${ }^{[6,34]}$ The bundle consisted of a two-hour training session for pediatric residents, adoption of a standardized mnemonic for verbal and written handoffs, and feedback by a chief resident or attending physician at least once per month. In a pilot study, medical errors were reduced from $33.8 \%$ pre-handoff educational program to $18.3 \%$ post. Preventable adverse events decreased from $3.3 \%$ to $1.5 \% .^{[6]}$ In the multi-center prospective evaluation of the same resident Handoff Bundle, the medical error rate was reduced by $23 \%$ and preventable adverse events decreased by $30 \%$ in a review of 10,740 admissions at nine participating pediatric teaching institutions. ${ }^{[34]}$ Based in part because of the demonstrated success of this educational bundle for medical residents, and because of the deficits noted in our curriculum related to handoff education, the decision was made to develop a similar educational bundle for our nursing students called the Nursing Handoff Educational Bundle (NHEB).

\subsection{Theoretical framework}

The Systems Engineering Initiative Model of Work System and Patient Safety (SEIPS) is the theoretical framework used for implementation of the NHEB. ${ }^{[35]}$ Figure 1 demonstrates Carayon et al.'s framework (2006), and Figure 2 represents this author's application of the framework to handoff education. The SEIPS work system includes system components such as technology and tools, (such as a handoff template), tasks (cognitive load), organizational and environmental factors (handoff setting, noise, interruptions), and people (education, skills, and knowledge). This complex work system affects care processes, such as the handoff, which can impact patient outcomes, quality of care, and employee and organizational outcomes. ${ }^{[35]}$ The education, or lack of education in the handoff process is one factor that can affect handoff outcome measures and patient outcomes.

\subsection{Aim and research questions}

The aim of this pilot study was to assess the effect of a NHEB in the development of handoff communication skills. The following program evaluation questions were asked:

- In the group of nursing students who received the intervention, what was the effect of the NHEB on performance of the handoff provider at the end of 15 weeks, compared to performance of a matched com- parison group of students who did not participate in the NHEB?

- In the group of nursing students who received the intervention, what was the effect of the NHEB on performance of the handoff receiver at the end of 15 weeks, compared to performance of a matched comparison group of students who did not participate in the NHEB?

- This pilot project also sought to evaluate how the students perceived the effectiveness of the Handoff Workshop.

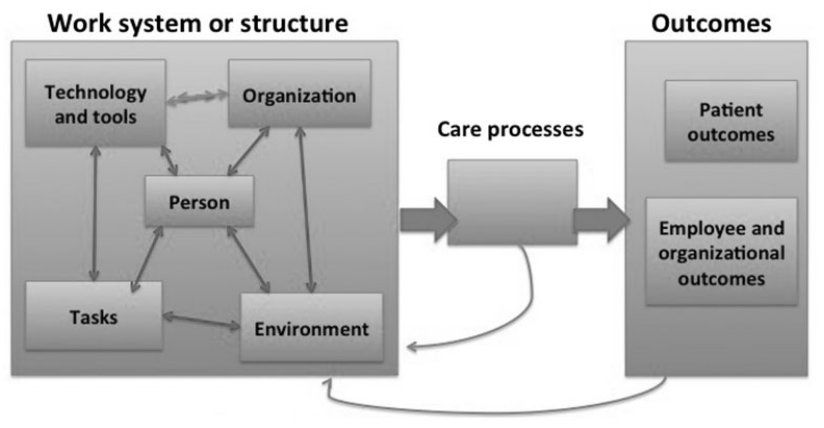

Figure 1. SEIPS model

SEIPS model: Systems Engineering Initiative for Patient Safety (Carayon et al. 2006) ${ }^{[35]}$

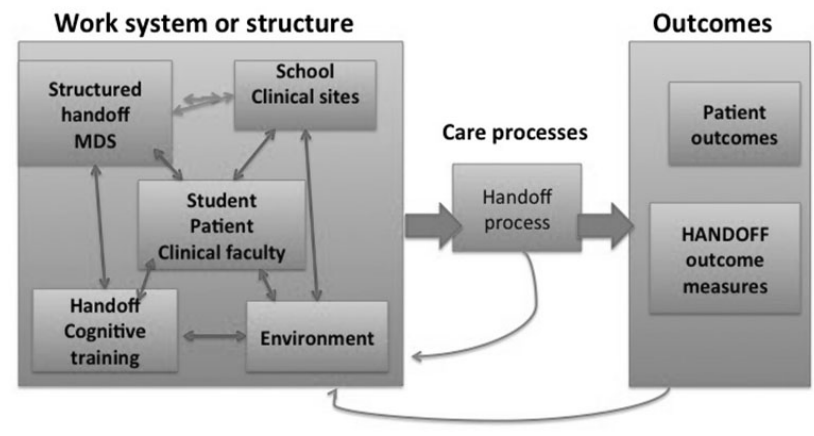

Figure 2. SEIPS model for handoffs SEIPS model: Application to handoff education ${ }^{[35]}$

\section{Methods}

\subsection{Project design}

A pretest, posttest design was used. Student results in the group who received the NHEB were compared to a comparison group who did not receive the intervention.

\subsection{Participants}

All second-semester students enrolled in an ABS in Nursing program at a large University in the Northeastern United States were invited to participate in the NHEB pilot study. Only students who progressed from second semester, summer 2014 to third semester, fall 2014 in the same cohort were 
eligible for participation. Informed consent was obtained from all participants. Of 30 students who were initially eligible to participate, 28 completed the pilot study. Reasons for attrition related to failure to progress in the nursing program.

\subsection{Setting}

Students were assigned to clinical experiences on medicalsurgical telemetry units at four different University-affiliated teaching hospitals. Clinical instructors all held a Masters Degree in Nursing and each had at least 25 years of clinical experience and a minimum of five years of nursing educational experience.

The four clinical sites that were available for student placement for third semester Adult Health II clinical experiences were randomly assigned to be either interventional or comparison sites. Sites A and B were designated to be interventional, and sites $\mathrm{C}$ and $\mathrm{D}$ were designated to be the comparison sites. Students were then allocated to the interventional or the comparison groups based on clinical site placement by University School of Nursing personnel who were blinded to the study. Placement into clinical sites was made in the usual fashion by considering student requests, and by reviewing academic and clinical progress.

\subsection{Instruments}

All handoffs were measured with the Handoff Clinical Examination (CEX) (see Table 1). The Handoff CEX is a tool that has been used to measure physician and nursing handoffs. ${ }^{[17,27,36]}$ The tool, as designed, has six domains measuring handoff organization, communication skills, content, clinical judgment, setting, patient-centered measures, and an overall score. Each domain is measured on a 1-9 scale, ranging from lowest to highest performance. Descriptive anchors at the low and high end of the scale assist the scorer. The Handoff CEX measures the performance of the handoff provider as well as the receiver. Spearman correlation coefficients among the subdomains of the tool ranged from 0.71-0.92 for all domains except setting. ${ }^{[17,36]}$ The Handoff CEX revealed a Cronbach alpha of 0.95 in reliability testing with Medical School faculty. ${ }^{[27]}$ For the purposes of this pilot study, the setting of the student handoffs was controlled, so this domain was not measured. Setting was controlled as a variable by moving data collection to a quiet, confidential area away from the patient room. Also, the patient-centered domain was eliminated from measurement to prevent introduction of a confounding variable in two out of four clinical sites that had implemented bedside handoffs.

The Handoff workshop was evaluated with the Handoff Workshop Participant Evaluation tool, a ten-item Likert survey tool with open-ended comments. The tool was adapted from a resident handoff workshop tool used in a multicenter trial. ${ }^{[37]}$ Responses were scored on a five-point Likert scale from strongly disagree to strongly agree. The questions asked participants to rate how well the workshop was able to meet major learning objectives. In addition, participants were asked to rate the workshop's content, structure, pace, and perceived relevance. Open-ended comments were collated and reported.

\subsection{Data collection procedures}

\subsubsection{Pre-test data collection}

Observation and assessment of handoff quality was evaluated at baseline and at the end of a 15-week period. Baseline observation was conducted during the Adult Health I course clinical experiences at the end of the second semester of a four-semester ABS program. Students were observed providing and receiving handoff report to each other in a quiet, confidential area at the end of the clinical day. Prior to the data collection, each student self-selected one of their assigned patients to hand off to another student. Each handoff receiver was instructed to prepare to receive handoff report as if they were accepting responsibility for the patient assignment. Students' handoffs were scored using the Handoff CEX tool. The primary investigator observed and scored all handoff measurements.

\subsubsection{Intervention}

The NHEB consisted of a three-hour handoff workshop for nursing students, a two-hour training session for clinical faculty, and formative evaluation and feedback for students during clinical experiences throughout their third semester. The three-hour workshop for students was incorporated into the clinical laboratory experience and clinical orientation routinely held at the beginning of the third semester of the ABS program in the Adult Health II course. The workshop included content in focused communication strategies from TeamSTEPPS ${ }^{[38]}$ and in best practices for nursing handoffs. ${ }^{[39]}$ TeamSTEPPS content included characteristics of high performing teams, methods to build a shared mental model, concepts of situational awareness, cross monitoring, debriefs, check-backs, closed loop communication, "sterile cockpit" and situation-background-assessmentrecommendation (SBAR) for handoff. Best practices relating to bedside handoffs were also discussed. ${ }^{[40]}$ Throughout the workshop, the active role of the handoff recipient in safety communication was stressed. The workshop format and TeamSTEPPS content was adapted from the curriculum used in the medical resident handoff education bundle. ${ }^{[33,37]}$ Teaching strategies included a didactic presentation, short video clips, simulation through role-play using case studies, and practice giving and receiving handoff using case studies 
(see Figure 3).

The case studies used for the simulation portion of the workshop included scenarios surrounding a patient diagnosed with pneumonia, a patient diagnosed with heart failure, and a patient post abdominal surgery. Students were divided into groups of three. Each student was given the opportunity to participate in each role as a handoff provider, a handoff recipient, and an observer. Students were provided with a brief case study and a partially completed SBAR tool. Key information was purposefully left off the SBAR, adding complexity to the simulation, as recommended by Cleland et al. ${ }^{[23]}$ Missing information included content such as allergies, fall risk, abnormal breath sounds, plan of care, or discharge planning needs. The provider and the receiver had the opportunity to create a shared mental model by asking questions, clarifying, and supplying or requesting missing information. Following each handoff, faculty led a debriefing. Peer review was incorporated into handoff practice when the student, in the role as observer, provided feedback using the Handoff CEX. All participants had the opportunity to discuss the simulation.

Table 1. Handoff Clinical Examination (CEX)

\begin{tabular}{|c|c|c|c|c|c|c|c|c|c|c|}
\hline \multicolumn{11}{|l|}{ Handoff CEX: Receiver Evaluation } \\
\hline Setting & 1 & 2 & 3 & 4 & 4 & 6 & 7 & 8 & 9 & \\
\hline Interruptions, noisy & & & & & & & & & & no interruptions, silent \\
\hline Organization & 1 & 2 & 3 & 4 & 5 & 6 & 7 & 8 & 9 & \\
\hline Disorganized & & & & & & & & & & Prepared for note-taking \\
\hline Ill-prepared & & & & & & & & & & Takes notes \\
\hline Communication & 1 & 2 & 3 & 4 & 5 & 6 & 7 & 8 & 9 & \\
\hline No interaction & & & & & & & & & & Face to face \\
\hline No questioning & & & & & & & & & & Asks questions \\
\hline No acceptance of responsibility for tasks & & & & & & & & & & Read-back of assigned tasks \\
\hline Vague language & & & & & & & & & & Concrete language \\
\hline Clinical Judgment & 1 & 2 & 3 & 4 & 5 & 6 & 7 & 8 & 9 & \\
\hline No recognition of sick patients & & & & & & & & & & Sick patients recognized \\
\hline No request for anticipatory guidance & & & & & & & & & & Anticipatory guidance requested \\
\hline Patient-centered & 1 & 2 & 3 & 4 & 5 & 6 & 7 & 8 & 9 & \\
\hline Inappropriate comments & & & & & & & & & & Includes patient/family in care \\
\hline Overall Receiver Handoff & 1 & 2 & 3 & 4 & 5 & 6 & 7 & 8 & 9 & \\
\hline \multicolumn{11}{|l|}{ Handoff CEX: Provider Evaluation } \\
\hline Setting & 1 & 2 & 3 & 4 & 4 & 6 & 7 & 8 & 9 & \\
\hline Interruptions, noisy & & & & & & & & & & no interruptions, silent \\
\hline Disorganized & & & & & & & & & & Used standardized template \\
\hline Rambling & & & & & & & & & & Concise \\
\hline Communication Skills & 1 & 2 & 3 & 4 & 5 & 6 & 7 & 8 & 9 & \\
\hline Understanding not confirmed & & & & & & & & & & Confirms understanding \\
\hline No time for questions & & & & & & & & & & Elicits questions \\
\hline Responsibility for tasks unclear & & & & & & & & & & Assigns responsibilities for tasks \\
\hline Vague language & & & & & & & & & & Concrete language \\
\hline Content & 1 & 2 & 3 & 4 & 5 & 6 & 7 & 8 & 9 & \\
\hline Information omitted or irrelevant & & & & & & & & & & Includes all essential information \\
\hline Omits clinical condition, to do’s & & & & & & & & & & Describes clinical condition \\
\hline Lacks plan or rationale & & & & & & & & & & Describes to do list, plan, and rationale \\
\hline Clinical Judgment & 1 & 2 & 3 & 4 & 5 & 6 & 7 & 8 & 9 & \\
\hline No recognition of sick patients & & & & & & & & & & Sick patients identified \\
\hline No anticipatory guidance & & & & & & & & & & $\begin{array}{l}\text { Anticipatory guidance provided with } \\
\text { plan of action }\end{array}$ \\
\hline Patient-centered & 1 & 2 & 3 & 4 & 5 & 6 & 7 & 8 & 9 & \\
\hline Inappropriate comments & & & & & & & & & & Includes patient/family in care \\
\hline Overall Provider Handoff & 1 & 2 & 3 & 4 & 5 & 6 & 7 & 8 & 9 & \\
\hline
\end{tabular}

* Handoff CEX ${ }^{[17,27,36]}$ 


\begin{tabular}{|c|c|}
\hline $\begin{array}{c}\text { Clinical Faculty } \\
\text { Education }\end{array}$ & $\begin{array}{l}\text { - Best Handoff Practice } \\
\text { - Use of Handoff CEX for formative evaluation }\end{array}$ \\
\hline Handoff Workshop & $\begin{array}{l}\text { - TeamSTEPPS, Best handoff practices } \\
\text { - Role Play Simulation with Case Studies }\end{array}$ \\
\hline $\begin{array}{c}\text { Standardized } \\
\text { Template for handoff. }\end{array}$ & $\begin{array}{l}\text { - Situation-Background-Assessment- } \\
\text { Recommentation (SBAR) }\end{array}$ \\
\hline $\begin{array}{c}\text { Standardized } \\
\text { Formative Evaluation }\end{array}$ & - Handoff CEX tool \\
\hline
\end{tabular}

Figure 3. NHEB intervention

As part of the Handoff Bundle, the interventional group clinical faculty were trained in handoff best practices, use of the SBAR handoff minimum data set, and handoff formative assessment and debriefing strategies using the Handoff CEX tool. Following the student workshop, clinical faculty in the intervention group provided weekly supervision of handoffs and formative evaluation throughout their third-semester clinical experiences using the Handoff CEX tool.

The students in the two comparison clinical groups received the usual clinical experiences throughout their semester, including any usual feedback from clinical faculty related to handoffs. At the end of the third semester, the Handoff Education was provided to the comparison group students and clinical instructors, following completion of all data collection. Total clinical hours were the same in both groups.

\subsubsection{Post-test data collection}

Toward the end of the 15-week period, the primary investigator again observed and scored student performance while providing and receiving handoffs during scheduled clinical experiences. The same testing conditions and procedures were used in the post-test as were described in the pre-test data collection. Handoff quality was scored using the Handoff CEX. The data from the post-test Handoff CEX was not considered in the students' official clinical evaluation.

\subsection{Data analysis procedures}

Data was analyzed using the IBM SPSS statistical package version 22. There was no missing data. Handoff CEX tool reliability was measured with Cronbach's alpha and was found to be satisfactory at 0.95 . Descriptive analysis of frequency, mean and standard deviation were analyzed. An examination of test assumptions indicated a satisfactory level of data normality, so an independent samples t-test was used to make inferential comparisons between the intervention and the comparison groups. First, the intervention and comparison group mean CEX scores were compared to assess for significant difference between groups at baseline. Next, the changes in Handoff CEX scores from pre-test to posttest were computed in SPSS by subtracting post-test scores from pre-test scores. Finally the relationship between handoff education and the change in mean Handoff CEX scores was determined using independent sample $t$-tests. Statistical significance was determined at an alpha level $(p)$ of .05 .

\subsection{Ethical consideration}

Institution review board approval was received from the two sponsoring universities, as well from all four clinical institutions where students were engaged in clinical experiences. Informed consent was obtained from all participants. Risks, benefits, and participant rights were explained to all eligible students prior to obtaining informed consent. Participation in the study, lack of participation, or data obtained during the study had no bearing on students' course grade or progression through the nursing program.

\section{RESUlTS}

The mean age of the participants was 30.3 years of age (range $24-46), 86 \%$ of the participants were female, $14 \%$ male.

\subsection{Handoff CEX results}

At baseline, there were no significant differences between the intervention and comparison groups in any measured domains (see Table 2). However, a significant training effect was seen in the intervention group mean in both handoff provider and handoff recipient change scores at post-test, compared to the comparison group (see Figures 4 and 5). The handoff provider overall mean score in the intervention group improved by a mean of 4.64 out of $7(\mathrm{SD}=1.27)$, while the comparison group only improved by 1.5 (SD = 1.34). This difference was found to be statistically significant $(t=7.33, p=.000)$. The handoff recipient scores in the intervention group reflected an even greater improvement compared to the control group with a mean overall improvement of 5.5 out of 7, compared to negligible improvement in the recipient comparison group $(\mathrm{m}=[0.36], \mathrm{SD}=1.39),(t=$ $12.7, p=.000)$. These findings suggest that the NHEB had a positive effect on Handoff CEX scores.

The greatest training effect was seen in the handoff recipient change scores in the intervention group compared to those in the recipient comparison group. As seen in Table 2, handoff receivers in both the intervention and comparison groups received very low scores at baseline. At posttest, students in the comparison group continued to score poorly when receiving handoff, reflecting the passivity of the receiver. However, with training, handoff receivers in the intervention group demonstrated notable improvement in all domains. Figures 4 and 5 illustrate the mean improvement in Handoff CEX scores in each subdomain and grouping, for both Handoff providers and receivers. 


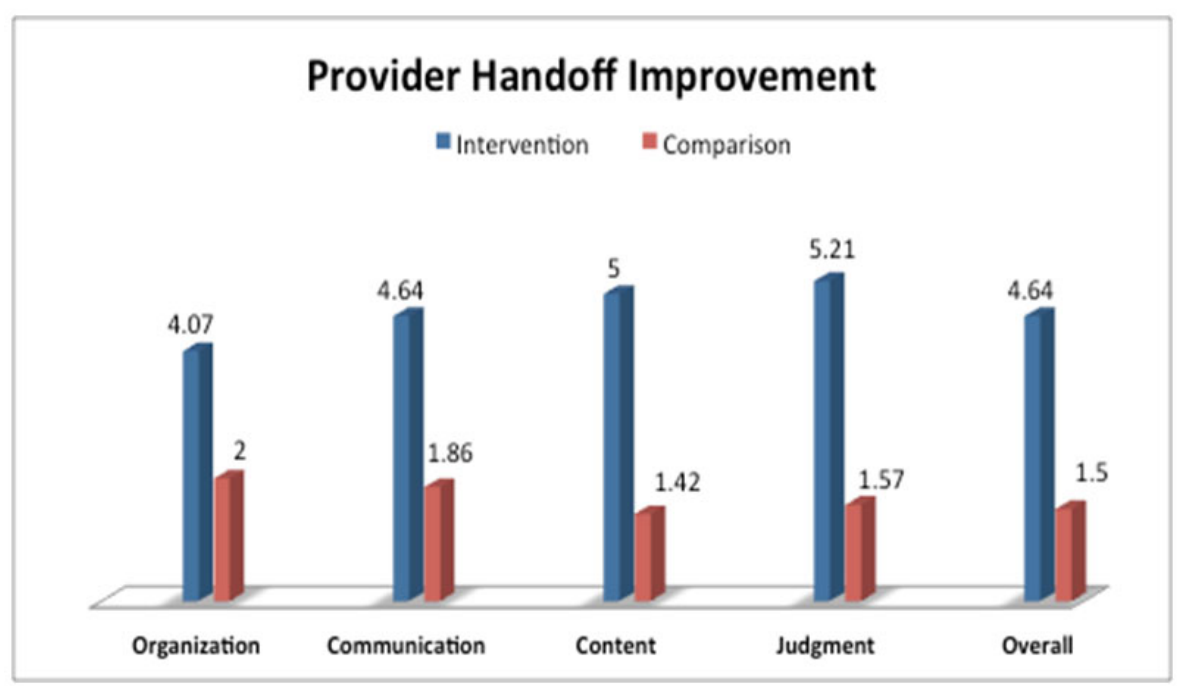

Figure 4. Handoff CEX improvements: Provider mean scores

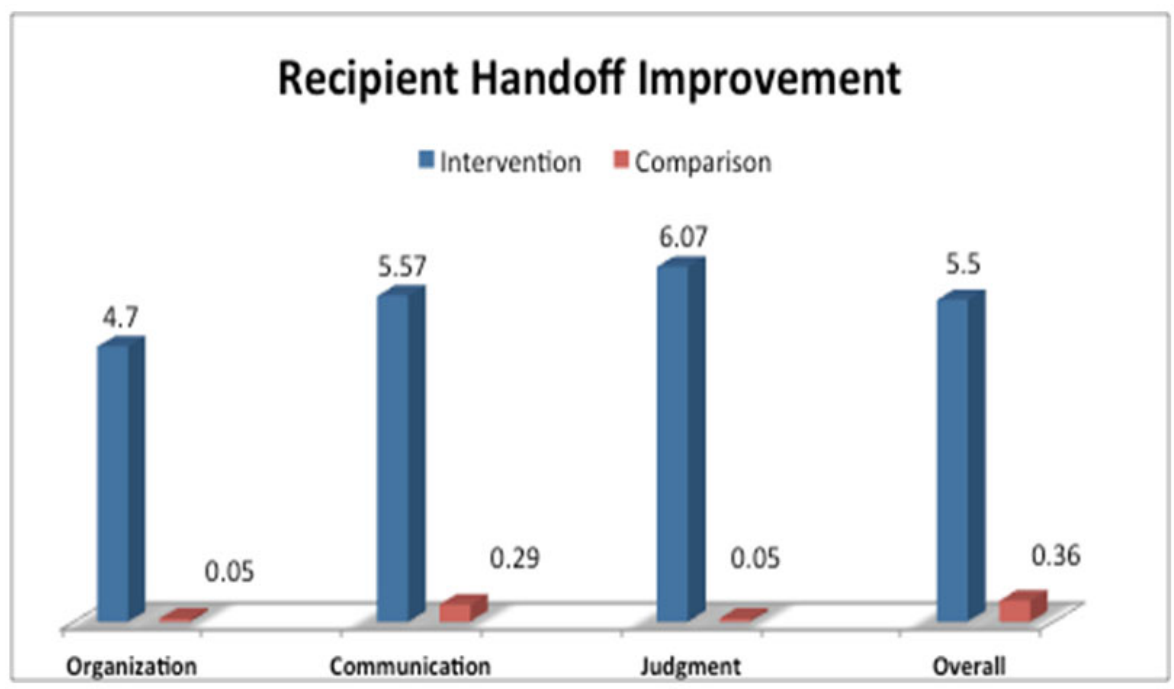

Figure 5. Handoff CEX improvement: Recipient mean scores

Table 2. Pretest handoff CEX: Overall mean scores

\begin{tabular}{lllll}
\hline & Total & Mean (SD) & $\boldsymbol{t}$ & $\boldsymbol{p}$ value \\
\hline Provider Intervention & $\mathrm{n}=14$ & $2.57(1.2)$ & 0.65 & \multirow{2}{*}{$.642(\mathrm{~ns})$} \\
Provider Comparison & $\mathrm{n}=14$ & $2.86(1.2)$ & 0.65 & \\
Recipient Intervention & $\mathrm{n}=14$ & $1.57(0.9)$ & 0.203 & 1 (ns) \\
Recipient Comparison & $\mathrm{n}=14$ & $1.64(0.9)$ & 0.203 & \\
\hline
\end{tabular}

\subsection{Handoff workshop participant evaluation}

Table 3 describes the workshop evaluation scores. Mean scores for all questions ranged from 4.64-4.85 out of five. In open-ended comments, most students listed the role-play

Published by Sciedu Press activity as the most effective element of the workshop. Additionally, students commented that they wished to see more examples of effective nursing handoffs using the SBAR format during the workshop. 
Table 3. Handoff participant workshop data $(n=14)$

\begin{tabular}{lll}
\hline After participating in the workshop, I am able to: & Mean (SD) & Range \\
\hline $\begin{array}{l}\text { Describe the behaviors of the handoff provider that promote the development of a shared mental } \\
\text { model during handoff. }\end{array}$ & $4.57(.5)$ & $4-5$ \\
$\begin{array}{l}\text { Describe the behaviors of the handoff recipient that promotes the development of a shared } \\
\text { mental model during handoff. }\end{array}$ & $4.79(.43)$ & $4-5$ \\
Recite and describe the individual elements of the SBAR mnemonic & $4.79(.43)$ & $4-5$ \\
Describe the behaviors that promote patient-centered care during a bedside handoff. & $4.86(.36)$ & $4-5$ \\
Describe best practices to improve the safety of handoffs. & $4.79(.43)$ & $4-5$ \\
\hline This Workshop: & Mean (SD) & Range \\
\hline Provided me with knowledge and skills relevant to my patient care activities & $4.64(.5)$ & $4-5$ \\
Was designed with an appropriate balance of lecture and interactive elements & $4.71(.47)$ & $4-5$ \\
Had an appropriate pace & $4.71(.47)$ & $4-5$ \\
Seemed to be the correct length to address the content & $4.64(.5)$ & $4-5$ \\
\hline
\end{tabular}

\section{DisCussion}

The findings in this pilot study suggest that nursing students performed significantly better when providing and receiving handoff after training compared to their peers who were assigned to the comparison group. In particular, the improvement in handoff recipient scores in the intervention group was most prominent. The handoff recipient scores in the intervention group improved by 5.5, while negligible improvement was seen in the comparison group scores. The passivity of the receivers seen in the comparison group is consistent with prior findings. ${ }^{[2,15,16]}$ The suggestion that handoff communication is improved with training is also consistent with prior findings. ${ }^{[6,15,25]}$ This pilot study is unique, however, by its focus on the handoff communication practices nursing students. Additionally, though Rayo ${ }^{[15]}$ has described the positive effect of handoff training in physician and nurse handoff receiver skills, this pilot study quantifies the effect of training on the recipient skills in nursing student handoffs. Without handoff education, the nursing students in this study lacked awareness of the importance of an active handoff recipient in creating a shared mental model. Cohen et al. ${ }^{[14]}$ describe the necessity of both provider and receiver actively participating in the co-construction of the oncoming caregiver's understanding of the patient in order to promote patient safety.

Since there were only two clinical faculty members in the interventional group, no quantitative data was gathered from clinical faculty. However, the clinical faculty noted that the Handoff CEX tool provided a standardized, consistent method to give feedback to students in the clinical area. Faculty provided feedback to students on handoffs over the course of the semester, including weekly one-on-one feedback, and the Handoff CEX provided the structure. In addition, faculty incorporated formative handoff evaluation with peer feedback into post-conference activities at least once during the semester.

In our experience, most clinical faculty readily provide feedback to students on handoff effectiveness. However, without a standardized program, there is no way to predict whether or not students receive consistent, accurate instruction followed by consistent handoff supervision with a standardized evaluation method. This pilot study suggests that the NHEB may be a feasible way to provide a standardized approach to the handoff education and evaluation of nursing students. Workshop evaluation scores were positive, suggesting that students found value in the formal educational session.

The NHEB provides a standardized educational program for students and clinical faculty, a standardized template for use in providing and receiving handoffs, and formative evaluation during clinical experiences using a standardized tool. Either the original Handoff CEX or a newer, validated shortened version ${ }^{[27]}$ could readily be incorporated into a curricular clinical evaluation tool for nursing students and adapted for local needs.

A handoff is an interaction between the provider and recipient. This interaction was only indirectly reflected in the provider and recipient scores, but was directly observed by the investigator during data collection. The investigator noted that provider scores improved in the presence of an active handoff recipient. For example, a handoff provider may have initially omitted important content. However, through questioning by the recipient, the information was ultimately conveyed. Though provider and recipient scores were reported separately, the handoff scores were truly generated through dyad cooperation, supporting the co-constructed mental model described by Cohen et al. ${ }^{[14]}$ This interaction may account for the high scores in both provider and recipient intervention groups and illustrates the positive effects of a shared mental model. 
Prelicensure curricular content must provide the necessary education to reduce patient safety risks related to unsafe handoff communication practices. ${ }^{[9]}$ Clinical experiences provide rich opportunities for situational learning in complex environments. If structured properly, the inter-shift handoff can provide opportunities for nursing students to gain important communication skills. However, in our experience, nursing students are frequently not included as active participants in the team that is handing off, leaving students out of the communication loop. For example, the handoff may not include patient background information if the patient is familiar to the nurses participating in handoff. Without encouragement, students rarely ask questions during the handoff. As a result, students are disengaged from the safety processes involved in handoff and therefore do not develop the necessary skills that lead to effective communication. Academia and clinical sites must partner to maximize learning opportunities for safety education during clinical experiences. Gore et al. ${ }^{[19]}$ describe the role of faculty as "culture brokers" when advocating for positive clinical experiences for nursing students.

\section{Conclusion}

The findings of this pilot study suggest that the NHEB improved handoff communication skills in a cohort of ABS nursing students. The NHEB includes an evidence-based educational handoff workshop, formal handoff training for clinical faculty, use of a standardized handoff template, and a structured formative evaluation tool for use during clinical experiences. It may be feasible to adapt and incorporate this educational bundle into the curricular clinical education of nursing students. Quality, Safety, Education, and Nursing (QSEN) competencies in patient-centered care, quality improvement, safety, teamwork, and collaboration are addressed by promoting safe, patient-centered and effective handoffs. ${ }^{[9]}$

\section{Limitations}

This pilot study had several limitations. First, this study was conducted to evaluate the implementation of a NHEB into the prelicensure curriculum in one School of Nursing using one cohort of students. Therefore, findings should be interpreted with caution. Transferability of findings to another University or to other settings may not be assumed. Secondly, students were not randomized into clinical groups. Instead, the clinicial sites were randomized to be either interventional or comparison and then students were placed into clinical sites in the usual fashion by a School of Nursing official blinded to the study. It is unclear whether characteristics of the clinical sites or clinical instructors could have accounted for differences in student outcomes. Finally, it is unknown whether the improvement in nursing student handoff skills translates to reductions in adverse events and medical errors, as this was not measured.

\section{FUTURE RESEARCH}

Future investigation with larger sample sizes and multiple settings is warranted to substantially evaluate the effectiveness of the NHEB. In this current study, students were not grouped into dyads for the purpose of studying the influence of the handoff receiver on handoff provider scores. Further study using a different design is recommended to quantify the influence of the receiver on provider scores and to evaluate the influence of the shared mental model on the overall handoff. Finally, since novice nurses do not consistently receive structured handoff education, ${ }^{[3]}$ future research should evaluate the effectiveness of a NHEB with new graduate nurses, including nurses hired into nurse residency programs. A well-designed, sufficiently powered study modeled after the Starmer study ${ }^{[6]}$ may evaluate the effects of handoff communication education on adverse events and near-misses in novice nurses.

\section{ACKNOWLEDGeMENTS}

The authors wish to gratefully acknowledge Renee Cantwell, DNP, RN, CNE, CPHQ for her guidance, mentorship, and significant contributions in the implementation of this project and review of the manuscript. We would also like to graciously thank Jane Ryan, PhD, MSN, CNM, Marianne Bryant, MSN, RN, JD, Mary Bozzo, MSN, RN, CCRN, Donna Cybulski, MSN, RN, Rachael Stavoli, MSN, RN, CCRN, APN-c, Joseph Avallone, William Bannon Jr., PhD, and the Rutgers University School of Nursing-Camden ABS nursing students for their assistance and participation in this project.

\section{Conflicts of InTERest Disclosure}

The authors declare that there is no conflict of interest statement.

\section{REFERENCES}

[1] Friesen MA, White SV, Byers JF. Handoffs: Implications for Nurses. In: Hughes RG, editor. Patient Safety and Quality: An EvidenceBased Handbook for Nurses. Advances in Patient Safety. Rockville
(MD). 2008.

[2] Holly C, Poletick EB. A systematic review on the transfer of information during nurse transitions in care. J Clin Nurs. 2014; 23(17-18): 2387-95. PMid:23786673 http://dx.doi.org/10.1111/jocn. 
12365

[3] Riesenberg LA, Leitzsch J, Cunningham JM. Nursing handoffs: a systematic review of the literature. The American Journal of Nursing. 2010; 110(4): 24-34. PMid:20335686 http://dx.doi .org/1 0.1097/01.NAJ .0000370154.79857.09

[4] Thomas MJ, Schultz TJ, Hannaford N, et al. Failures in transition: learning from incidents relating to clinical handover in acute care. Journal for healthcare quality: official publication of the National Association for Healthcare Quality. 2013; 35(3): 49-56. PMid:22268639 http://dx.doi .org/10.1111/j.1945-1474.2011.00189.x

[5] Arora V, Johnson J, Lovinger D, et al. Communication failures in patient sign-out and suggestions for improvement: a critical incident analysis. Quality \& safety in health care. 2005; 14(6): 401-7. PMid:16326783 http://dx.doi.org/10.1136/qshc. 20 05.015107

[6] Starmer AJ, Sectish TC, Simon DW, et al. Rates of medical errors and preventable adverse events among hospitalized children following implementation of a resident handoff bundle. Jama. 2013; 310(21): 2262-70. PMid:24302089 http://dx.doi.org/10.1001/jama. 2013. 281961

[7] Hill W, Nyce J. Human Factors at Change of Shift Report; A review of reliability and resilience principles applied to change of shift report (CoSR). Canadian Journal of Respiratory Therapy. 2010; 46(1): 44-51.

[8] Ebright PR, Urden L, Patterson E, et al. Themes surrounding novice nurse near-miss and adverse event situation. The Journal of Nursing Administration. 2004; 34(11): 531-8. http://dx.doi.org/10.10 97/00005110-200411000-00010

[9] Cronenwett L, Sherwood G, Barnsteiner J, et al. Quality and Safety Education for Nurses. Nursing outlook. 2007; 55(3): 12231. PMid:17524799 http://dx.doi.org/10.1016/j.outlook .2007 .02 .006

[10] Barnsteiner J. Teaching the culture of safety. Online journal of issues in nursing. 2011; 16(3): 5. PMid:22324571

[11] Barton AJ, Armstrong G, Preheim G, et al. A national Delphi to determine developmental progression of quality and safety competencies in nursing education. Nursing outlook. 2009; 57(6): 313 22. PMid:19942032 http://dx.doi.org/10.1016/j.outlook .2009 .08 .003

[12] Van Eaton E. Handoff improvement: we need to understand what we are trying to fix. Joint Commission journal on quality and patient safety/Joint Commission Resources. 2010; 36(2): 51.

[13] Mathieu JE, Heffner TS, Goodwin GF, et al. The influence of shared mental models on team process and performance. Journal of applied psychology. 2000; 85(2): 273. http://dx.doi.org/10.1037/0 021-9010.85.2.273

[14] Cohen MD, Hilligoss B, Kajdacsy-Balla Amaral AC. A handoff is not a telegram: an understanding of the patient is co-constructed. Critical Care. 2012; 16(1): 303. PMid:22316097 http://dx.doi .org/10.1186/cc10536

[15] Rayo MF, Mount-Campbell AF, O'Brien JM, et al. Interactive questioning in critical care during handovers: a transcript analysis of communication behaviours by physicians, nurses and nurse practitioners. BMJ quality \& safety. 2014; 23(6): 483-9. PMid:24336577 http://dx.doi.org/10.1136/bmjqs-2013-002341

[16] Taylor C. Assessing patients' needs: does the same information guide expert and novice nurses? International Nursing Review. 2002; 49(1): 11-9. http://dx.doi.org/10.1046/j.1466-765 7.2002.00098.x

[17] Horwitz LI, Dombroski J, Murphy TE, et al. Validation of a handoff assessment tool: the Handoff CEX. J Clin Nurs. 2013; 22(9-10):
1477-86. PMid:22671983 http://dx.doi.org/10.1111/j.136 5-2702.2012.04131.x

[18] Kesten KS. Role-play using SBAR technique to improve observed communication skills in senior nursing students. The Journal of Nursing Education. 2011; 50(2): 79-87. PMid:21210611 http: //dx.doi.org/10.3928/01484834-20101230-02

[19] Gore A, Leasure AR, Carithers C, et al. Integrating hand-off communication into undergraduate nursing clinical courses. Journal of Nursing Education and Practice. 2015; 5(4): 70-6. http://dx . doi . org/10.5430/jnep.v5n4p70

[20] Aebersold M, Tschannen D, Sculli G. Improving nursing students' communication skills using crew resource management strategies. The Journal of nursing education. 2013; 52(3): 125-30. PMid:23380022 http://dx.doi.org/10.3928/01484834-201 30205-01

[21] Tschannen D, McClish D, Aebersold M, et al. Targeted communication intervention using nursing crew resource management principles. J Nurs Care Qual. 2015; 30(1): 7-11. PMid:25279547 http://dx.doi.org/10.1097/NCQ.0000000000000073

[22] Kalisch BJ, Aebersold M, McLaughlin M, et al. An intervention to improve nursing teamwork using virtual simulation. Western journal of nursing research. 2015; 37(2): 164-79. PMid:24763705 http://dx.doi.org/10.1177/0193945914531458

[23] Cleland JA, Ross S, Miller SC, et al. "There is a chain of Chinese whispers ...": empirical data support the call to formally teach handover to prequalification doctors. Quality \& Safety in Health Care. 2009; 18(4): 267-71. PMid:19651929 http://dx.doi.org/10. 1136 /qshc. 2008.029983

[24] Accreditation Council for Graduate Medical Education (ACGME). Common Program Requirements. 2013.

[25] Allen S, Caton C, Cluver J, et al. Targeting improvements in patient safety at a large academic center: an institutional handoff curriculum for graduate medical education. Academic medicine: Journal of the Association of American Medical Colleges. 2014; 89(10): 1366-9. PMid:25119553 http://dx.doi.org/10.1097 /ACM. 0000000000000462

[26] Arora VM, Greenstein EA, Woodruff JN, et al. Implementing peer evaluation of handoffs: associations with experience and workload. Journal of Hospital Medicine: An Official Publication of the Society of Hospital Medicine. 2013; 8(3): 132-6. PMid:23382137 http://dx.doi.org/10.1002/jhm. 2002

[27] Arora VM, Berhie S, Horwitz L, et al. Using standardized videos to validate a measure of Handoff quality: the handoff mini-clinical examination exercise. Journal of Hospital Medicine. 2014; 9(7): 441-6. PMid:24665068 http://dx.doi.org/10.1002/jhm. 2185

[28] Aylward M, Nixon J, Gladding S. An entrustable professional activity (EPA) for handoffs as a model for EPA assessment development. Academic Medicine: Journal of the Association of American Medical Colleges. 2014; 89(10): 1335-40. PMid:24892402 http://dx.doi.org/10.1097/ACM.0000000000000317

[29] Farnan JM, Paro JA, Rodriguez RM, et al. Hand-off education and evaluation: piloting the observed simulated hand-off experience (OSHE). Journal of General Internal Medicine. 2010; 25(2): 129-34. PMid:19924489 http://dx.doi.org/10.1007/s11606-009-1 170-y

[30] Graham KL, Marcantonio ER, Huang GC, et al. Effect of a systems intervention on the quality and safety of patient handoffs in an internal medicine residency program. Journal of General Internal Medicine. 2013; 28(8): 986-93. PMid:23595931 http: //dx.doi.org/10.1007/s11606-013-2391-7

[31] Sawatsky AP, Mikhael JR, Punatar AD, et al. The effects of deliberate practice and feedback to teach standardized handoff com- 
munication on the knowledge, attitudes, and practices of first-year residents. Teaching and Learning in Medicine. 2013; 25(4): 27984. PMid:24112195 http://dx.doi.org/10.1080/10401334. 2013.827970

[32] Stoyanov S, Boshuizen $\mathrm{H}$, Groene $\mathrm{O}$, et al. Mapping and assessing clinical handover training interventions. BMJ Quality \& Safety. 2012; 21 (Suppl 1): i50-7. PMid:23077279 http://dx.doi .org/10.11 36/bmjqs-2012-001169

[33] O'Toole JK, West DC, Starmer AJ, et al. Placing faculty development front and center in a multisite educational initiative: lessons from the I-PASS Handoff study. Academic Pediatrics. 2014; 14(3): 221-4. PMid:24767774 http://dx.doi.org/10.1016/j . acap. 2014.02 .013

[34] Starmer AJ, Spector ND, Srivastava R, et al. Changes in medical errors after implementation of a handoff program. The New England Journal of Medicine. 2014; 371(19): 1803-12. PMid:25372088 http://dx.doi.org/10.1056/NEJMsa1405556

[35] Carayon P, Schoofs HA, Karsh BT, et al. Work system design for patient safety: the SEIPS model. Quality \& Safety in Health Care. 2006; 15(Suppl 1): i50-8. PMid:17142610 http://dx.doi.org/1 $0.1136 /$ qshc. 2005.015842
[36] Horwitz LI, Rand D, Staisiunas P, et al. Development of a handoff evaluation tool for shift-to-shift physician handoffs: the Handoff CEX. Journal of Hospital Medicine: An Official Publication of the Society of Hospital Medicine. 2013; 8(4): 191-200. PMid:23559502 http://dx.doi.org/10.1002/jhm. 2023

[37] Starmer AJ, Spector ND, Srivastava R, et al. I-pass, a mnemonic to standardize verbal handoffs. Pediatrics. 2012; 129(2): 201 4. PMid:22232313 http://dx.doi.org/10.1542/peds. 2011 $-2966$

[38] Agency for Healthcare Research and Quality (AHRQ). TeamSTEPPS 2.0 Course Management Guide. [cited 2015 March 17]. Available from: http://www.ahrq.gov/professionals/educati on/curriculum-tools/teamstepps/instructor/

[39] Dufault M, Duquette CE, Ehmann J, et al. Translating an EvidenceBased Protocol for Nurse-to-Nurse Shift Handoffs. Worldviews on Evidence-Based Nursing. 2010; 7(2): 59-75. http://dx.doi.org $/ 10.1111 / j .1741-6787.2010 .00189 . x$

[40] Sand-Jecklin K, Sherman J. A quantitative assessment of patient and nurse outcomes of bedside nursing report implementation. J Clin Nurs. 2014; 23(19-20): 2854-63. PMid:24606553 http://dx.doi . org/10.1111/jocn. 12575 